\title{
List of 'prurient' research stirs fear, anger among US scientists
}

A 'hit list' of more than 150 National Institutes of Health (NIH)-funded scientists conducting behavioral research on HIV/AIDS transmission, homosexuality and drug abuse is stirring anger and fear in the scientific community.

The Traditional Values Coalition, which says it represents more than 43,000 US churches, compiled a list of what it calls "smarmy," "prurient" and "provocative" research and is demanding that the $\mathrm{NIH}$ justify funding the projects. In response, the NIH has asked some of the researchers to write summaries defending their work.

"The list is a source of concern for researchers on two levels," says Ken Mayer, director of Brown University's AIDS program. "It is making scientists anxious about whether their research will be targeted, and it is creating disincentives to developing effective HIV-prevention programs."
To prevent the spread of AIDS, it is important to understand triggers and cultural influences on behavior, Mayer says. "Two decades of carefully done research of what works and not in HIV prevention tells us it must be culturally specific," he says. The coalition is allowing ideology to get in the way of data-driven science, he adds.

Bonnie Halpern-Felsher, a researcher at the University of California in San Francisco, says an NIH program officer told her that her current grant was not under question, but she might have to be concerned about future grants. She studies adolescent risk judgment and HIV infection.

Even those scientists who don't agree with all the research projects say the list questions the peer-review process. "The peer-review process needs to prevail," says HalpernFelsher.

The list is only the latest in a series of efforts by conservative religious organizations to censor science that they find distasteful or morally repugnant, says Judith Auerbach, vice president of public policy at the American Foundation for AIDS Research.

In July 2003, the House of Representatives narrowly missed pulling funding from five research grants on sexual behavior. At a Congressional hearing in early October, NIH director Elias Zerhouni was asked to provide a written explanation for a number of grants, after which he was given the longer 'hit list', says Auerbach. The upcoming NIH reauthorization hearings can also be used to strengthen, add to, or define the outer limits of funding for certain research areas, Auerbach notes.

"We are concerned with the larger context in which the list is appearing," she says.

"Where is this all going?"

Vicki Brower, New York

\section{Fatal flaw in baby formula sparks reform in Israeli ministry}

A German baby formula that caused severe vitamin deficiency in 15 Israeli infants and killed 2 has led to a radical revamp of Israel's regulatory framework for infant formula, making the requirements more stringent than for pharmaceuticals.

In early November, several Israeli babies were hospitalized with the neurologic and cardiac symptoms of beriberi, a severe deficiency in thiamine, or vitamin B1. Thiamine has essential roles in converting carbohydrates to energy and in the synthesis of the neurotransmitter acetylcholine.

The infants had all been fed Remedia Super Soya 1, a kosher infant formula manufactured exclusively for Israel by the German company Humana. The affair prompted a police investigation in both Israel and Germany. Subsequent testing revealed that, contrary to product labels, the formula almost entirely lacked thiamine. The product has since been withdrawn from the market.

Humana, the oldest and one of the largest baby food companies in Germany, admitted to a series of blunders and fired four workers. According to a company spokesman, a Humana employee failed to add thiamine to the product because the vitamin naturally occurs in soybeans. The soy was treated with heat, however, which destroyed the thiamine.
Because follow-up quality testing didn't pick up on the deficiency, the scandal raised questions about the adequacy of the Israeli Health Ministry's supervision. In response, the Ministry changed its regulations for baby formulas. Previously, manufacturers had to submit laboratory test results for a formula's

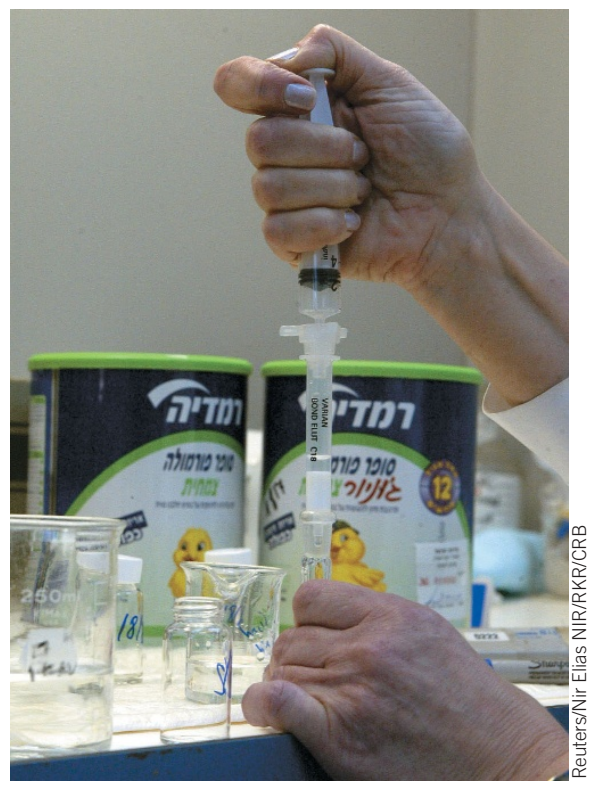

Recipe for disaster: A series of errors led to rare cases of beriberi, a deficiency of thiamine. ingredients, after which the Ministry performed random testing of selected ingredients. Under the new regulations, the Ministry will test all batches of locally produced or imported formulas.

In effect, the Ministry will be duplicating the quality assurance process of the manufacturer-a practice unheard of anywhere else in the world, says Dorit Nitzan-Kaluski, director of the Ministry's Food and Nutrition Administration. "It's a catastrophe for the country because it's a huge expense and a huge mess, but there's no choice," says Nitzan-Kaluski. "We've lost our credibility."

In the US, manufacturers submit lab tests for each new infant formula to the Food and Drug Administration, but the agency doesn't retest the formulas before they go to market. It does, however, perform annual inspections of manufacturing plants and collect samples for nutrient analyses.

Beriberi is rare in the US and in Europe because most foods there are vitaminenriched, and is seen primarily in chronic alcoholics or in people on dialysis. It is more common in parts of East Asia, where milled or polished rice is a dietary staple, but its incidence there has also dropped sharply as economic conditions have improved.

Luba Vikhanski, Tel Aviv 